\title{
PERFIL DE MULHERES COM ÚLCERAS DA PERNA DECORRENTES DE DOENÇA FALCIFORME
}

\author{
Paula Gabriela Andrade ${ }^{1, *}$ (D), Josimare Aparecida Otoni Spira² (D), \\ Maria de Lourdes Gomes ${ }^{4}$ (D), Eline Lima Borges ${ }^{3}$ (i)
}

\section{RESUMO}

Objetivo: caracterizar o perfil de mulheres com úlceras da perna decorrentes da doença falciforme atendidas em uma instituição pública de saúde do Brasil. Método: estudo de coorte histórica realizado no setor ambulatorial com amostra de mulheres com doença falciforme e úlcera da perna, acompanhadas de 1998 a 2014. Os dados foram extraídos do prontuário e contemplaram variáveis sociodemográficas, clínicas e relacionadas à úlcera, e passaram por análise estatística descritiva. Resultados: das 17 mulheres, 64,7\% obtiveram cura, 58,8\% tinham idade entre 30 e 39 anos, 64,7\% se autodeclaram pardas, 70,6\% estavam sem parceiros, 41,2\% possuíam ensino fundamental incompleto, 52,9\% tinham renda de 2 a 3 salários mínimos, 70,6\% eram eutróficas e 82,4\% faziam uso de suplementos vitamínicos. As mulheres apresentaram o total de 29 úlceras, 52,9\% tinham úlcera única, 41,4\% localizadas na região maleolar, 55,17\% com existência entre 2 e 36 meses, todas classificadas em estágio 3. O tratamento foi com coberturas e bota de Unna. Conclusão: as mulheres receberam cuidados de enfermeiros especialistas e a maioria obteve a cura com até oito meses de acompanhamento que demandou a consulta de enfermagem, contemplando a avaliação clínica, o tratamento tópico e aplicação da terapia de compressão.

DESCRITORES: Anemia falciforme. Úlcera da perna. Perfil de saúde. Estomaterapia.

\section{PROFILE OF WOMEN WITH LEG ULCERS DUE TO SICKLE CELL DISEASE}

\section{ABSTRACT}

Objective: to characterize the profile of women with leg ulcers resulting from sickle cell disease treated at a public health institution in Brazil. Method: historical cohort study conducted in the outpatient sector with a sample of women with sickle cell disease and leg ulcer, followed from 1998 to 2014 . The data were extracted from the medical record and included sociodemographic, clinical and ulcer-related variables, and underwent descriptive statistical analysis. Results: of the 17 women, $64.7 \%$ were cured, $58.8 \%$ were aged between 30 and 39 years, $64.7 \%$ declared themselves brown, $70.6 \%$ were without partners, $41.2 \%$ had incomplete elementary education, 52, 9\% had an income of 2 to 3 minimum wages, $70.6 \%$ were eutrophic and $82.4 \%$ used vitamin supplements. Women had a total of 29 ulcers, $52.9 \%$ had a single ulcer, $41.4 \%$ were located in the malleolar region, $55.17 \%$ were between 2 and 36 months, all classified as stage 3. The treatment was with coverings and Unna's boot. Conclusion: the women

1. Universidade Federal de Minas Gerais - Hospital das Clínicas - Ambulatório de Dermatologia - Belo Horizonte (MG), Brasil.

2. Universidade Federal de Minas Gerais - Escola de Enfermagem - Belo Horizonte (MG), Brasil.

3. Universidade Federal de Minas Gerais - Escola de Enfermagem - Departamento de Enfermagem Básica -

Belo Horizonte (MG), Brasil.

4. Escola Bahiana de Medicina e Saúde Pública - Salvador (BA), Brasil.

*Autora correspondente: paula_gabriela11@yahoo.com.br

Editor de Seção: Juliano T Moraes

Recebido: Dez. 14, 2020 | Aceito: Jan. 18, 2021

Como citar: Andrade PG; Spira JAO; Gomes ML ; Borges EL. Perfil de mulheres com úlceras da perna decorrentes de doença falciforme. ESTIMA, Braz. J. Enterostomal Ther., 2021, 19: e0321. https://doi.org/10.30886/estima.v19.993_PT 
received care from specialist nurses and most were cured with up to eight months of follow-up, which required a nursing consultation, including clinical evaluation, topical treatment and application of compression therapy.

DESCRIPTORS: Sickle cell anemia. Leg ulcer. Health profile. Stomatherapy.

\section{PERFIL DE MUJERES CON ÚLCERA DE LA PIERNA CONSECUENTE DE ENFERMEDAD DE CÉLULAS FALCIFORMES}

\section{RESUMEN}

Objetivo: caracterizar el perfil de mujeres con úlceras de la pierna consecuente de enfermedad de células falciformes atendidas en una institución pública de salud de Brasil. Método: estudio de cohorte histórica realizado en el sector ambulatorio con muestra de mujeres con enfermedad de células falciformes y úlcera de pierna, seguidas de 1998 a 2014. Los datos fueron extraídos de la ficha médica y abarcaron las variables sociodemográficas, clínicas y relacionadas con la úlcera y pasaron por análisis estadístico descriptivo. Resultados: de las 17 mujeres, el 64,7\% obtuvieron curación, el 58,8\% tenían edades entre 30 y 39 años, el 64,7\% se autodeclararon morenas, el 70,6\% no tenían pareja, el 41,2\% no habían completado la educación básica, el 52,9\% con ingresos de 2 a 3 sueldos mínimos, el 70,6\% eran eutróficas, el 82,4\% hacían uso de suplementos vitamínicos. Las mujeres presentaron un total de 29 úlceras, el 52,9\% tenían úlcera única, el 41,4\% ubicadas en la zona maleolar; el 55,17\% con existencia entre 2 y 36 meses, todas clasificadas en estadio 3. El tratamiento se dio con vendajes y bota de Unna. Conclusión: las mujeres recibieron cuidados de enfermeros especialistas y la mayoría obtuvo la curación con hasta ocho meses de seguimiento. Fueron sometidas a la consulta de enfermería, comprendiendo la evaluación clínica, el tratamiento tópico y la aplicación de terapia de compresión.

DESCRIPTORES: Anemia de Células Falciformes; Úlcera de la Pierna; Perfil de salud; Estomaterapia.

\section{INTRODUÇÃO}

A doença falciforme (DF) compreende um grupo de doenças genéticas e hereditárias causadas devido a uma mutação no gene estrutural da cadeia $\beta$-globina, resultando na hemoglobina $\mathrm{S}(\mathrm{HbS})$. A $\mathrm{HbS}$ quando desoxigenada sofre o processo de polimerização, com consequente alteração na forma do eritrócito (forma de foice), resultando em hemólise precoce e oclusão dos vasos, o que acarreta diversas repercussões clínicas ${ }^{1}$.

A HbS pode ser encontrada nos estados homozigótico e heterozigótico, sendo o primeiro a forma mais grave da doença, denominado anemia falciforme (HbSS). Já o estado heterozigótico, causado pela herança $\mathrm{HbS}$ em combinação com outra mutação na hemoglobina $\mathrm{A}(\mathrm{HbA})$, aparece em várias formas, sendo as mais comuns a $\mathrm{S}$ beta-talassemia, $\mathrm{S}$ alfa-talassemia, $\mathrm{HbSC}, \mathrm{HbSD}, \mathrm{HbSE}^{1}$.

A DF é mais frequente em povos africanos, mediterrâneos, asiáticos e chineses, embora as hemoglobinopatias que têm predileções étnicas estejam presentes em todos os continentes como consequência das migrações populacionais. No Brasil, devido à grande presença de afrodescendentes que são uma das bases da população do país, a DF constitui um grupo de doenças e agravos relevantes. A incidência é mais alta nos estados com maior concentração de afrodescendentes, sendo de 1:650 na Bahia, 1:1.200 no Rio de Janeiro e 1:1.400 nos estados de Minas Gerais, Maranhão, Pernambuco e Goiás².

Os avanços na medicina e na tecnologia têm diminuído a taxa de mortalidade de crianças com DF, entretanto essa doença ainda está associada a uma expectativa de vida mais curta em adultos. Um estudo analisou mais de 16.654 óbitos por DF entre 1979 e 2005, e revelou que a expectativa de vida média para mulheres era de 42 anos e de 38 anos para homens. A causa mais comum de morte, dentre as complicações da DF, foi a infecciosa ${ }^{3}$.

As complicações da DF são dolorosas, crônicas e/ou agudas, podem ocorrer precocemente e se estender por toda a vida. As mais comuns são anemias, crises álgicas, infecções recorrentes, icterícia, sequestro esplênico, síndrome torácica aguda, 
acidente vascular encefálico, priapismo, crise aplásica, osteonecrose e úlceras da perna ${ }^{4}$. Ao considerar o sexo feminino, acrescenta-se à lista de complicações o atraso da menarca, além das complicações em relação à gestação, pois cerca de 50\% das gestantes com DF requerem pelo menos uma internação hospitalar. Mesmo com os cuidados multidisciplinares atuais, a mortalidade é aumentada ${ }^{5}$.

As úlceras da perna ocorrem em pessoas de ambos os sexos e iniciam de forma aguda e, frequentemente, evoluem para fases crônicas. Essa situação requer manejo adequado e demanda recursos financeiros para investimento em produtos e insumos ${ }^{1}$.

A prevalência e incidência das úlceras da perna variam geograficamente, com a idade e com o tipo de doença ${ }^{6}$. Os resultados de um estudo realizado na Nigéria retrataram essas variações e constataram incidência de $0,45 \%$ e prevalência de $3,1 \%{ }^{7}$. Estudo multicêntrico realizado em três países, envolvendo 659 pessoas com DF identificou prevalência de úlcera da perna de 10,8\%, sendo 18,6\% em Ghana, 3,5\% na Itália e 2,4\% nos Estados Unidos, e a maior parte das úlceras da perna ocorreu em adultos com o genótipo $\mathrm{HbSS}^{8}$.

As úlceras da perna podem surgir após um trauma ou de forma espontânea, preferencialmente nos maléolos, podendo acometer toda circunferência da perna. São extremamente dolorosas e de difícil cicatrização, com evolução arrastada por meses a anos e altas taxas de recidiva ${ }^{6}$. As úlceras são mais comuns na segunda década de vida e em pessoas do sexo masculino. Estão associadas a um menor nível socioeconômico e à baixa escolaridade9 .

Úlceras da perna, independentemente da etiologia, podem não representar grande risco de morte para quem as possui, mas afetam as pessoas nas esferas física, psicossocial e emocional, principalmente pelo caráter progressivo e crônico ${ }^{6}$. Diante dessa complexidade, as pessoas com DF e úlcera da perna demandam serviços e profissionais especializados.

Embora resultados de estudos citem que as úlceras sejam mais comuns nos homens, chegando a uma proporção de $3: 1^{10}$ e $1,3: 1^{7}$, esta é uma importante temática de discussão devido ao impacto que pode causar na vida dos pacientes do sexo feminino. Mulheres que convivem com úlcera da perna experimentam situações estressantes advindas desse problema crônico de saúde, tais como dor, odor, alterações das atividades cotidianas, baixa autoestima e alterações ginecológicas ${ }^{11}$. Faz-se necessário considerar, ainda, a mudança que a úlcera traz para seu corpo, exigindo uma apresentação de si ao público no sentido de manter em segredo a existência da úlcera ${ }^{10}$.

A interação entre as pessoas com úlcera e os profissionais de saúde constitui-se em um elemento imprescindível na definição de cuidado ${ }^{12}$. Nesse contexto, o conhecimento do perfil de mulheres com úlcera da perna por DF é importante por se tratar de uma população que já apresenta complicações e preocupações características desse sexo, como o planejamento da vida reprodutiva, complicações da gravidez, bem como cuidado de um filho com $\mathrm{DF}^{5}$. Assim sendo, questiona-se: quem são as mulheres com úlcera da perna atendidas ambulatorialmente em um serviço público? O conhecimento gerado irá subsidiar o planejamento das ações de enfermagem, como também melhorar a relação entre profissionais de saúde e mulheres com úlcera da perna.

Diante do exposto, o estudo objetiva caracterizar o perfil de mulheres com úlcera da perna decorrente da DF atendidas em uma instituição pública de saúde do Brasil.

\section{MÉTODOS}

Trata-se de um estudo de coorte histórica, envolvendo o setor de Estomaterapia de um ambulatório de dermatologia de um hospital universitário terciário, de grande porte, de Belo Horizonte, Minas Gerais, Brasil. No referido setor, os profissionais responsáveis pelo cuidado direto às pessoas com úlceras são enfermeiros especialistas em estomaterapia ou dermatologia. A troca do curativo ocorre uma ou duas vezes na semana conforme avaliação da ferida. Nesse serviço, os pacientes são tratados conforme protocolo institucional. Para o manejo do edema é padronizada a terapia de compressão inelástica (bota de Unna) e como tratamento tópico as coberturas denominadas hidrocoloide, alginato de cálcio sem prata (Ag), carvão ativado com $\mathrm{Ag}$ ou espuma com $\mathrm{Ag}$.

A amostra foi composta por todas as mulheres com DF e úlcera da perna, com idade igual ou superior a 18 anos, atendidas no período de junho de 1998 a junho de 2014, quando ocorreu a admissão das mulheres. Durante o tratamento todas as 
pacientes utilizaram bota de Unna para manejo do edema e como tratamento tópico uma das coberturas padronizadas na instituição.

A coleta de dados foi realizada no período de junho a agosto de 2020 por um pesquisador do presente estudo. Os dados foram extraídos do prontuário do paciente e registrados em um formulário elaborado especificamente para a pesquisa, contemplando variáveis sociodemográficas (idade, cor/raça, estado marital, escolaridade, renda familiar, ocupação, saneamento básico), clínicas (índice de massa corporal [IMC], doenças associadas, medicamentos em uso, tabagismo, etilismo) e relacionadas à úlcera (número de úlceras, localização, tempo de existência, período necessário para cura, comprometimento tecidual [estágio 1: pele íntegra com eritema não branqueável; estágio 2: perda de pele em sua espessura parcial, envolvendo a epiderme e podendo chegar à derme; estágio 3: perda total da espessura da pele, envolvendo o tecido subcutâneo, podendo se estender à fáscia subjacente] $)^{13}$. Os dados coletados foram digitados em planilhas do programa Excel, versão 14.7.7, a fim de submetê-los à análise estatística descritiva.

A pesquisa respeitou as diretrizes da Resolução n. ${ }^{\circ}$ 466, de 12 de dezembro de 2012, do Conselho Nacional de Saúde. O projeto do estudo foi aprovado pelo Comitê de Ética em Pesquisa da Universidade Federal de Minas Gerais sob o parecer $\mathrm{n}^{\circ}$ 2.797.025/2018. Solicitou-se a dispensa do Termo de Consentimento Livre e Esclarecido, uma vez que se trata de um estudo observacional e os dados foram extraídos de fonte secundária.

\section{RESULTADOS}

No período de 16 anos foram admitidas e tratadas, no setor de Estomaterapia, 17 mulheres com úlcera da perna decorrente da DF. Dessas, 11 (64,7\%) alcançaram a completa epitelização da úlcera, 3 (17,6\%) foram transferidas para outros serviços, 2 (11,8\%) abandonaram o tratamento e 1(5,9\%) foi a óbito.

A maioria das mulheres tinha idade entre 30 e 39 anos, autodeclarou-se parda, estava sem parceiro e tinha renda familiar de 2 a 3 salários mínimos (Tabela 1). Quanto às variáveis clínicas, a maior parte era eutrófica, sem doenças associadas, fazia uso de suplementos vitamínicos e não fumava (Tabela 2).

Tabela 1. Distribuição quanto às variáveis sociodemográficas das mulheres com úlcera da perna decorrente de doença falciforme ( $n=17)$. Belo Horizonte (MG), Brasil - 2020.

\begin{tabular}{ll}
\hline Variáveis & $\mathbf{n = 1 7}(\%)$ \\
\hline Idade (anos) & $01(5,9)$ \\
\hline Até 19 & $04(23,5)$ \\
\hline $20-29$ & $10(58,8)$ \\
\hline $30-39$ & $02(11,8)$ \\
\hline 40 ou mais & \\
\hline Cor/ Raça & $11(64,7)$ \\
\hline Parda & $05(29,4)$ \\
\hline Preta & $01(5,9)$ \\
\hline Branca & $12(70,6)$ \\
\hline Estado Marital & $05(29,4)$ \\
\hline Sem parceiro & \\
\hline Com parceiro & $07(41,2)$ \\
\hline Escolaridade & $03(17,6)$ \\
\hline Ensino fundamental incompleto & $05(29,4)$ \\
\hline Ensino fundamental completo & $01(5,9)$ \\
\hline Ensino médio completo & $01(5,9)$ \\
\hline Ensino superior completo &
\end{tabular}


Tabela 1. Continuação...

\begin{tabular}{lc}
\hline Variáveis & $\mathbf{n = 1 7 ( \% )}$ \\
\hline Renda familiar (salário mínimo) & $05(29,4)$ \\
\hline 01 & $09(52,9)$ \\
\hline $02-03$ & $00(0,0)$ \\
\hline $04-05$ & $01(5,9)$ \\
\hline$>05$ & $02(11,8)$ \\
\hline Não informado & \\
\hline Saneamento básico & $16(94,1)$ \\
\hline Presente & $01(5,9)$ \\
\hline Ausente & \\
\hline Ocupação & $01(5,9)$ \\
\hline Estudante & $01(5,9)$ \\
\hline Auxiliar administrativa & $05(29,4)$ \\
\hline Do lar & $04(23,5)$ \\
\hline Doméstica & $03(17,6)$ \\
\hline Recepcionista & $01(5,9)$ \\
\hline Costureira & $01(5,9)$ \\
\hline Operadora de microfilmagem & $01(5,9)$ \\
\hline Professora (aula particular) &
\end{tabular}

Tabela 2. Distribuição quanto às variáveis clínicas das mulheres com úlcera da perna decorrente de doença falciforme (n=17). Belo Horizonte (MG), Brasil - 2020.

\begin{tabular}{|c|c|}
\hline Variáveis & $n=17(\%)$ \\
\hline \multicolumn{2}{|l|}{ Tabagismo } \\
\hline Sim & $01(5,9)$ \\
\hline Não & $16(94,1)$ \\
\hline \multicolumn{2}{|l|}{ Etilismo } \\
\hline Sim & $02(11,8)$ \\
\hline Não & $15(88,2)$ \\
\hline \multicolumn{2}{|l|}{ IMC (kg/m²) } \\
\hline$<18,5$ & $04(23,5)$ \\
\hline$\geq 18,5<25,0$ & $12(70,6)$ \\
\hline$\geq 25,0<30,0$ & $01(5,9)$ \\
\hline \multicolumn{2}{|l|}{ Doenças associadas* $^{*}$} \\
\hline Nenhuma & $13(76,4)$ \\
\hline Hipertensão arterial & $02(11,8)$ \\
\hline Rinite alérgica & $01(5,9)$ \\
\hline Câncer & $01(5,9)$ \\
\hline \multicolumn{2}{|l|}{ Medicamentos em uso } \\
\hline Analgésico & $06(35,3)$ \\
\hline Suplemento vitamínico & $14(82,4)$ \\
\hline Anti-hipertensivo & $02(11,8)$ \\
\hline Antiplaquetário & $02(11,8)$ \\
\hline Antidepressivo & $02(11,8)$ \\
\hline Quimioterápico & $01(5,9)$ \\
\hline Ácido fólico & $02(11,8)$ \\
\hline
\end{tabular}

IMC = Índice de Massa Corporal. "A variação no n deve-se a pessoas ter mais de uma doença associada. 
As 17 mulheres apresentaram o total de 29 úlceras, sendo que 9 (52,9\%) apresentaram úlcera única, $12(41,4 \%)$ estavam localizadas na região maleolar, 16 (55,17\%) com tempo de existência da ferida entre 2 e 36 meses, e em 9 (31,04\%) o tempo necessário para atingir a cura foi de 2 a 4 meses (Tabela 3).

Tabela 3. Distribuição das variáveis relacionadas às úlceras da perna $(n=29)$ das mulheres com doença falciforme ( $n=17)$. Belo Horizonte (MG), Brasil - 2020.

\begin{tabular}{|c|c|}
\hline Variáveis & $\mathrm{n}=17(\%)$ \\
\hline \multicolumn{2}{|l|}{$\mathrm{N}^{\circ}$ de úlcera } \\
\hline Uma & $09(52,9)$ \\
\hline Duas & $06(35,3)$ \\
\hline Três & $00(00)$ \\
\hline Quatro & $02(11,8)$ \\
\hline \multicolumn{2}{|l|}{ Localização } \\
\hline Maléolo medial & $12(41,4)$ \\
\hline Maléolo lateral direito & $09(31,0)$ \\
\hline Terço inferior da perna & $08(27,6)$ \\
\hline \multicolumn{2}{|c|}{ Comprometimento tecidual } \\
\hline Estágio 1 & $0(0)$ \\
\hline Estágio 2 & $0(0)$ \\
\hline Estágio 3 & $29(100)$ \\
\hline \multicolumn{2}{|c|}{ Tempo de existência da lesão } \\
\hline Menos de 2 meses & $1(3,44)$ \\
\hline De 2 a 36 meses & $16(55,17)$ \\
\hline De 37 a 48 meses & $1(3,45)$ \\
\hline De 49 a 60 meses & $2(6,89)$ \\
\hline De 61 a 96 meses & $3(10,34)$ \\
\hline$>96$ meses & $6(20,68)$ \\
\hline \multicolumn{2}{|c|}{ Tempo gasto para a cura das lesões } \\
\hline De 2 a 4 meses & $9(31,03)$ \\
\hline De 4 a 8 meses & $4(13,79)$ \\
\hline De 8 a 12 meses & $6(20,69)$ \\
\hline$>12$ meses & $2(6,89)$ \\
\hline Não se aplica* & $8(27,59)$ \\
\hline
\end{tabular}

*Estão inclusas nessa categoria as lesões de mulheres que não concluíram o tratamento, seja por abandono, transferência ou óbito.

Os tratamentos tópicos utilizados para o tratamento das úlceras foram hidrocoloide placa, alginato de cálcio, carvão ativado com Ag e espuma de poliuretano com Ag. O manejo do edema foi realizado com bota de Unna.

\section{DISCUSSÃO}

No presente estudo, $2(11,8 \%)$ mulheres tinham idade acima de 40 anos, sendo a mais velha com 43 anos. O achado corrobora o resultado de estudo francês com 98 pessoas com DF e úlcera da perna ativa ou com histórico prévio de úlcera, em que a média de idade foi 37 anos $(30-44)^{14}$. Essa informação é relevante, considerando que indivíduos nascidos com DF podem viver aproximadamente 22 anos a menos do que uma população de mesma raça/etnia e idade sem a $\mathrm{DF}^{15}$ e a expectativa de vida média para mulheres é de 42 anos $^{3}$. 
A úlcera da perna é um limitador para a inserção da mulher no mercado de trabalho ${ }^{6}$, o que pode estar associado ao fato das mulheres deste estudo terem baixa escolaridade e ocupação de baixa remuneração. Entretanto, ressalta-se que o percentual de famílias chefiadas por mulheres vem aumentando e, muitas vezes, elas têm papel central na promoção do bem-estar dos membros da família ${ }^{16}$.

Conviver com uma doença crônica compreende um processo complexo, cíclico, dinâmico e em constante mudança, que afeta as pessoas em todas as esferas de suas vidas. Sabe-se que mulheres e homens possuem percepção diferente do adoecimento. Enquanto as mulheres enfatizam aparência física (alteração da autoimagem), os homens se preocupam com a perda da força muscular, como a fraqueza ${ }^{12}$.

Mulheres com DF e úlcera da perna vivenciavam dor intensa e sentimentos de vergonha e de inutilidade, traduzidos em sofrimento, baixa autoestima e limitações na vida social, o que, por sua vez, pode motivar o comportamento de isolamento ${ }^{11}$. Essas alterações podem justificar o fato da maioria $(70,6 \%)$ das participantes do estudo não ter parceiros. Essa característica também foi encontrada em estudo brasileiro realizado com 14 mulheres com idade entre 23 e 61 anos que apresentavam úlcera da perna, sendo que $85 \%$ também não tinham parceiros ${ }^{17}$.

A origem africana da DF reflete nos achados desta investigação, ao constatar que 94,1\% das mulheres se autodeclaram pretas ou pardas. Dado semelhante foi identificado em resultado de estudo realizado em Recife, no Brasil, com 30 pessoas com DF, das quais $80 \%$ se declararam de cor preta ou parda ${ }^{18}$.

O nível de escolaridade é cêntrico para muitas das consequências sociais, fato percebido nas mulheres do estudo e confirmado por outra pesquisa realizada com pessoas com DF cuja escolaridade foi inferior a das pessoas sem a doença $(\mathrm{p}=0,020)^{19}$. Essa situação pode se agravar na ocorrência da úlcera da perna, uma vez que é sabido que a sua presença tem efeitos deletérios em relação à educação, emprego, recreação e vida conjugal e familiar. Quando comparadas pessoas com a DF com e sem a úlcera, aquelas com úlcera abandonaram a escola com uma idade significativamente menor (14,4 anos) do que as sem úlcera $(16,1)(\mathrm{p}<0,01)^{19}$.

É lastimável, mas a DF não é uma doença amplamente conhecida nas instituições de ensino, mesmo quando há alunos com o diagnóstico matriculados. Esse fato limita o envolvimento da escola com os problemas vivenciados pelo estudante ${ }^{20}$, contribuindo para a evasão precoce e reforçando a relevância da educação na mudança dos indicadores sociais.

Ao relacionar escolaridade, atividades laborais e renda, percebe-se um círculo vicioso no qual as repercussões clínicas da doença levam o sujeito a ter baixa escolaridade e consequentemente empregos com pouca remuneração, perpetuando, assim, a baixa renda. Quando comparadas pessoas com e sem a DF, a diferença da renda familiar é estatisticamente significante, visto que maior número de pessoas com DF tem renda menor ou igual a um salário mínimo quando comparado com aquelas sem a doença ${ }^{18}$.

Resultado de estudo americano apresenta dados comprovando que indivíduos com úlcera da perna têm pior função física $(\mathrm{p}=0,0022)$ e a dor interfere mais em sua vida diária $(0,0003)$ quando comparados às pessoas com a DF sem úlcera ${ }^{11}$. Essa condição clínica crônica afeta negativamente as atividades laborais e, consequentemente, a renda, visto que, neste estudo, $52,9 \%$ das mulheres eram do lar ou empregadas domésticas e 66,7\% tinham renda familiar de até um salário mínimo.

Os padrões de recreação das pessoas com DF em geral estão afetados e elas tendem a ser sedentárias ${ }^{21}$. No entanto, nesta pesquisa, apenas 5,9\% tinham sobrepeso. O National Health Service da Inglaterra recomenda o encaminhamento de pessoas com sobrepeso ou obesidade à equipe multiprofissional para adoção de intervenções comportamentais 5 .

Mulheres com DF são mais propensas a complicações quando comparadas a mulheres sem a DF ${ }^{5}$. Entretanto, no presente estudo, 23,6\% das mulheres tinham hipertensão arterial sistêmica, câncer ou rinite alérgica. É importante que durante a consulta de enfermagem o profissional faça a anamnese cuidadosa, uma vez que a cura de lesões cutâneas é afetada por fatores sistêmicos, como idade, vascularização, medicação sistêmica, estado nutricional, tabagismo e doença primária9.

Um dos medicamentos, até o momento considerado a terapia medicamentosa mais eficaz na prevenção de crises e complicações nas pessoas com DF é a hidroxiureia, seu uso reduz o risco de óbito pela DF e diminui significativamente o número anual de episódios álgicos agudos em adultos, mas um possível efeito colateral são as úlceras da perna22. Diante de tantos benefícios, constata-se, nesta pesquisa, que nenhuma mulher fazia uso dessa medicação. Esse fato deve-se, provavelmente, à suspeita da hidroxiureia provocar úlceras da perna em pacientes com DF. Contudo, esse efeito colateral 
permanece controverso ${ }^{23}$, inclusive em uma revisão sistemática da literatura o tratamento com hidroxiureia de pessoas com DF não foi significativamente associado a um aumento na ocorrência de úlceras da perna ${ }^{22}$.

As pessoas com DF enfrentam outra situação de sofrimento que são as síndromes de dor falciforme crônica que incluem úlceras da perna ${ }^{4}$. Elas são complicações dolorosas e frequentemente incapacitantes. A dor na úlcera geralmente é classificada de moderada a intensa ${ }^{14}$ e na maioria das vezes opioides orais ou parenterais são necessários para obter alívio da dor ${ }^{13}$. Na investigação deste estudo, 35,3\% das mulheres faziam uso de analgésicos, dado inferior ao encontrado em um estudo realizado na África com 40 pessoas com úlcera da perna, que foi de $80 \%{ }^{24}$. O dado relacionado à prescrição de analgésico para as mulheres deste estudo pode indicar o subtratamento da dor. Pessoas com DF e dor crônica podem apresentar problemas psicológicos graves, ocasionando até o afastamento das atividades sociais, e sua gestão exige dos profissionais de saúde paciência, compreensão e empatia ao longo do tratamento ${ }^{4}$.

Quanto às características das úlceras, essas têm margens bem definidas, bordas levemente elevadas e leito recoberto, predominantemente, por esfacelo entremeando o tecido de granulação vermelho pálido. Podem ser classificadas como agudas, quando cicatrizam em menos de um mês, e crônicas, em caso contrário ${ }^{25}$. Neste estudo, todas as lesões foram classificadas em estágio $3^{13}$, uma vez que apresentavam perda total da espessura da pele, envolviam o tecido subcutâneo e estendiam à fáscia subjacente, contudo não comprometiam estruturas mais profundas.

As úlceras ocorrem com maior frequência ao redor dos maléolos mediais e laterais, mas também podem surgir na região tibial anterior e no dorso do pé. Os fatores da predileção da úlcera pelo maléolo são o reduzido fluxo sanguíneo local, alta pressão venosa, menor quantidade de gordura subcutânea, pele fina e linfedema ${ }^{13}$. Neste estudo, $72,4 \%$ das úlceras estavam presentes nas regiões dos maléolos medial e/ou lateral, dado que corrobora achados cuja predileção da úlcera foi na região de maléolo em $86 \% \%^{7}$ e $66,7 \%{ }^{10}$ dos casos. Além da predileção pela região do maléolo, as úlceras geralmente são únicas em $58 \%{ }^{10}, 76 \%{ }^{24}$ e $69 \%{ }^{14}$ das pessoas. Nesta investigação, $52,9 \%$ das mulheres apresentaram uma úlcera, porcentagem inferior quando comparada aos estudos citados.

$\mathrm{Na}$ presente pesquisa, as feridas foram classificadas como crônicas com tempo de existência entre 2 meses e 10 anos, sendo que 55,17\% tinham tempo de duração entre 2 e 18 meses. Um estudo realizado na Nigéria apresentou dado semelhante, em torno de 79\% dos participantes apresentavam tempo de duração da úlcera entre 7 e 18 meses ${ }^{7}$. Um estudo multicêntrico realizado em Ghana, Itália e Estados Unidos, envolvendo 659 pessoas com DF, identificou duração média das úlceras da perna de 4,6 anos e a duração média mais longa foi de 7,25 anos ${ }^{8}$, diferente do presente estudo, em que 20,68\% das participantes apresentavam úlcera por mais de 10 anos.

O tempo de duração da úlcera é um fator preditivo de cura. A duração menor que 9 semanas foi significativamente $(\mathrm{p}=0,024)$ associada a uma maior chance de cura, com odds ratio $3,19(1,16-8,76)^{14}$. Seis meses de existência definem as úlceras recalcitrantes ${ }^{13}$.

Dentre as participantes deste estudo que obtiveram a cura, 31,03\% demandaram de 2 a 4 meses, com tratamento tópico e controle do edema apropriados, conforme as recomendações para o manejo da úlcera da perna em pessoas com $\mathrm{DF}^{26}$. O tratamento tópico das úlceras envolveu a utilização de coberturas, como hidrocoloide placa, alginato de cálcio, carvão ativado com $\mathrm{Ag}$ e espuma de poliuretano com Ag. Esses produtos mantêm o ambiente úmido, promovem o desbridamento de tecido desvitalizado e controlam a carga bacteriana ou infecção $0^{5}$.

O manejo do edema foi realizado por meio da utilização da bota de Unna. Sabe-se que a insuficiência venosa é frequentemente observada em pessoas com DF, portanto, além do tratamento tópico da úlcera, é necessário realizar o manejo do edema da perna com o uso de terapias de contenção (bota de Unna) ou de compressão (sistemas de multicomponentes), sendo esse último o de primeira escolha ${ }^{6,5}$.

Vale destacar que o tamanho amostral foi uma limitação do estudo, imposta pelo pequeno número de mulheres admitidas no cenário do estudo, desse modo a validade externa fica comprometida. No entanto, os resultados da pesquisa contribuíram para conhecer os perfis sociodemográficos e clínicos das mulheres com DF, incluindo as características das úlceras. Permitiram também estabelecer um diálogo com os dados da literatura, considerando as convergências e divergências. Com isso, o conhecimento gerado revelou lacunas, inclusive a baixa produção científica sobre a temática tratada: mulheres com DF e úlcera da perna. 
Outro benefício obtido por meio das informações extraídas do prontuário, previamente coletadas durante a consulta realizada pelo enfermeiro, e analisadas neste estudo é que elas permitem ao examinador avaliar quais comportamentos necessitam de intervenções de educação em saúde. Além disso, possibilita seguir as recomendações de tratamento das úlceras da perna decorrentes da DF e desmistificar a inexistência de cura dessas lesões cutâneas.

\section{CONCLUSÃO}

As 17 mulheres com DF apresentaram 29 úlceras, sendo que a maioria apresentava úlcera única e tempo de existência da ferida entre 2 e 36 meses. No setor de Estomaterapia onde o estudo foi realizado, as mulheres recebiam cuidados de enfermeiros especialistas e a maior parte obteve a cura com até oito meses de acompanhamento que demandou consulta de enfermagem, contemplando a avaliação clínica, o tratamento tópico e aplicação da terapia de compressão. Os suplementos vitamínicos foram as medicações mais utilizadas. A maioria das mulheres encontrava-se na faixa etária entre 30 e 39 anos, autodeclarou-se de cor preta/parda e não possuía companheiro. A escolaridade e a renda familiar eram baixas.

Ressalta-se que este estudo se ateve a dados sociodemográficos e clínicos de mulheres com úlceras da perna. Considerando a complexidade que a úlcera acarreta na vida dessas pessoas, percebeu-se a necessidade da realização de estudos qualitativos que abordem as questões psicossociais trazidas pela presença da úlcera.

\section{CONTRIBUIÇÃO DOS AUTORES}

Conceitualização: Borges EL e Andrade PG; Metodologia: Borges EL, Spira JAO e Andrade PG; Redação - Primeira Versão: Spira JAO, Andrade PG e Gomes ML; Redação - Revisão \& Edição: Andrade PG, Spira JAO, Borges EL e Gomes ML; Supervisão: Borges EL.

\section{DISPONIBILIDADE DE DADOS DE PESQUISA}

Os dados da pesquisa serão enviados mediante solicitação e após aprovação dos autores.

\section{REFERÊNCIAS}

1. Sundd P, Gladwin MT, Novelli EM. Pathophysiology of Sickle Cell Disease. Annu Rev Pathol 2019;14:263-92. https://doi. org/10.1146/annurev-pathmechdis-012418-012838

2. Ministério da Saúde (BR). Doença falciforme: condutas básicas para tratamento. Brasília(DF): Secretaria de Atenção à Saúde; 2012.

3. Lanzkron S, Carroll P, Jr Haywood C. Mortality Rates and Age at Death from Sickle Cell Disease: U.S., 1979-2005. Public Health Rep 201;128(2):110-116. https://doi.org/10.1177/003335491312800206

4. Ballas SK, Darbari DS. Review/overview of pain in sickle cell disease. Complement Ther Med 2020;49:102327. https://doi. org/10.1016/j.ctim.2020.102327

5. National Institutes of Health (NIH). Evidence-based management of sickle cell disease: expert panel report 2014. 2014. [citado em 28 nov 2020]. Disponível em: https://www.nhlbi.nih.gov/sites/default/files/media/docs/sickle-cell-disease-report\%20 020816_0.pdf

6. Minniti CP, Kato GJ. How we treat sickle cell patients with leg ulcers. Am J Hematol 2016;91(1):22-30. https://doi.org/10.1002/ ajh.24134

7. Hassan A, Gayus DL, Abdulrasheed I, Umar MA, Ismail DL, Babadoko AA. Chronic leg ulcers in sickle cell disease patients in Zaria, Nigeria. Arch Int Surg 2014;4(3)141-45. https://doi.org/10.4103/2278-9596.146405

8. Antwi-Boasiako C, Andemariam B, Colombatti R, Asare EV, Strunk C, Piccone CM et al. A study of the geographic distribution and associated risk factors of leg ulcers within an international cohort of sickle cell disease patients: the CASiRe group analysis. Ann Hematol 2020;99(9):2073-79. https://doi.org/10.1007/s00277-020,-04057-8 
9. AIDallal SM. Mini review: leg ulcers - a secondary complication of sickle cell disease. Int J Gen Med 2019;12:279-82. https://doi. org/10.2147/IJGM.S217369

10. Bazuaye GN, Nwannadi Al, Olayemi EE. Leg ulcers in adult sickle cell disease patients in Benin city, Nigeria. GomalJournal of Medical sciences 2010; [citado em 26 nov 2020];8(2):190-4. Disponível em: https://www.researchgate.net/publication/216180367_Leg_ Ulcers_in_Adult_sickle_cell_disease_patients_in_Benin_City_Nigeria

11. Umeh NI, Ajegba B, Buscetta AJ, Abdallah KE, Minniti CP, Bonham VL. The psychosocial impact of leg ulcers in patients with sickle cell disease: I don't want them to know my little secret. PLoS One 2017;12(10):e0186270. https://doi.org/10.1371/journal. pone.0186270

12. Cordeiro RC, Ferreira SL, Santos ACC. O adoecimento de mulheres e homens com anemia falciforme: um estudo de Grounded Theory. Rev Latino-Am Enfermagem 2015;23(6):1113-20. https://doi.org/10.1590/0104-1169.0594.2656

13. Minniti CP, Eckman J, Sebastiani P, Steinberg MH, Ballas SK. Leg ulcers in sickle cell disease. Am J Hematol 2010;85(10):831-3. https:/doi.org/10.1002/ajh.21838

14. Senet $P$, Blas-Chatelain C, Levy P, Manea EM, Peschanski M, Mirault T et al. Factors predictive of leg-ulcer healing in sickle cell disease: a multicentre, prospective cohort study. Br J Dermatol 2017;177(1): 206-11. https://doi.org/10.1111/bjd.15241

15. Lubeck D, Agodoa I, Bhakta N, Denese M, Pappu K, Howard R et al. Estimated Life Expectancy and Income of Patients With Sickle Cell Disease Compared With Those Without Sickle Cell Disease. JAMA Netw Open 2019;2(11):e1915374. https://doi. org/10.1001/jamanetworkopen.2019.15374

16. Cavenaghi S. Mulheres chefes de família no Brasil: avanços e desafios. Rio de Janeiro: ENS-CPES, 2018; [Citado em 26 nov 2020] Estudos sobre seguros, $\mathrm{n}^{\circ}$ 32. Disponivel em: https://www.ens.edu.br/arquivos/mulheres-chefes-de-familia-no-brasil-estudosobre-seguro-edicao-32_1_2.pdf

17. Lacerda FKL, Ferreira SL, Nascimento ER, Costa DO, Cordeiro RC. Self-care deficits in women with leg ulcers and sickle cell disease. Rev Bras Enferm 2019;72(Suppl 3):78-85. http://doi.org/10.1590/0034-7167-2018-0005

18. Alexandre MRA, Pedrosa EN, Soares PHS, Wanderley MM, Melo RVM, Correa MSM et al. Qualidade de vida de mulheres com doença falciforme atendidas em um hospital terciário no Recife, Brasil. R bras Qual Vida 2019; [citado em 24 nov 2020]; 11(3):e10156. Disponível em: http://periodicos.utfpr.edu.br/rbqv

19. Lima KTLL, Pereira JOF, Reis PRM, Alcântara KC, Rodrigues FM. Qualidade de vida dos portadores de doença falciforme. Rev enferm UFPE on line 2019;13(2):424-30. Disponível em: https://pesquisa.bvsalud.org/portal/resource/pt/biblio-1010204

20. Rodrigues WCC, Seibert CS, Silva KLF. Um olhar sobre a formação do aluno com doença falciforme. Desafios (Palmas) 2017;4(1):86-94. http://doi.org/10.20873/uft.2359-3652.2017v4n1p86

21. Kaufman K, Chin S-H, Kahathuduwa C, Wood MMA, Feliu M, Hill L et al. Psychosocial Correlates, Pain and Activities of Daily Living in Sickle Cell Disease Patients. Progress in Preventive Medicine 2018;3(4):e0019. https://doi.org/10.1097/pp9.0000000000000019

22. Nevitt SJ, Jones AP, Howard J. Hydroxyurea (hydroxycarbamide) for sickle cell disease. Cochrane Database Syst Rev 2017;4(4):CD002202. https://doi.org/10.1002/14651858.CD002202.pub2

23. Monfort J-B, Senet P. Leg Ulcers in Sickle-Cell Disease: Treatment Update. Adv Wound Care (New Rochelle) 2020;9(6):348-56. https://doi.org/10.1089/wound.2018.0918

24. Ndiaye M, Niang SO, Diop A, Diallo M, Diaz K, Ly F et al. Leg ulcers in sickle cell disease: A retrospective study of 40 cases. Ann Dermatol Venereol 2016;143(2):103-7. http://doi.org/10.1016/j.annder.2015.12.004

25. Singh AP, Minniti CP. Leg ulceration in sickle cell disease: an early and visible sign of end-Organ Disease. Sickle Cell Disease Pain and Common Chronic Complications 2016. http://doi.org/10.5772/64234

26. Borges EL, Spira JAO, Garcia TF. Recomendações para o manejo da úlcera da perna em pessoas com doença falciforme. Rev enferm UERJ 2020;28:e50170. https://doi.org/10.12957/reuerj.2020.50170 